\title{
低速走行中の車両タイヤ振動におけるエネルギハーベスティングのモデル解析
}

\author{
張 云順 ${ }^{* 1}$ ，鄭 仁成 ${ }^{* 2}$, 江尻 賢治*2，蘇 東旭 ${ }^{* 1}$, 中野 公彦*3
}

\section{Modelling analysis for vibration energy harvesting excited by low-speed automobile tires}

\author{
Yunshun ZHANG ${ }^{* 1}$, Rencheng ZHENG ${ }^{* 2}$, Kenji EJIRI ${ }^{* 2}$, Dongxu SU $^{* 1}$ and Kimihiko NAKANO*3 \\ ${ }^{* 1,{ }^{*}}$ Institute of Industrial Science, The University of Tokyo \\ 4-6-1 Komaba, Meguro-ku, Tokyo 153-8505, Japan \\ ${ }^{* 3}$ Interfaculty Initiative in Information Studies, The University of Tokyo \\ 4-6-1 Komaba, Meguro-ku, Tokyo 153-8505, Japan
}

Received 13 December 2015

\begin{abstract}
This study reports a vibrational energy harvesting system applied for low-speed vehicle tires on the asphalt road. The systematic model was analyzed under the measured road noise, in which a cantilever beam pasted piezoelectric film and magnets with the same polarity are fabricated as a nonlinear bistable vibrating system, when vehicle travels on the asphalt road at the different speeds of $10-20 \mathrm{~km} / \mathrm{h}$. By the theoretical investigation and simulation study, in the case of combination of a periodic modulating force which is autonomously offered from the gravitational effect of the magnetic end mass with the tire rotation and a vertical road noise excitation which is produced by the interaction of the tire and road surface, it can be observed that the potential becomes practically realizable to stimulate stochastic resonance, which can apparently enhance energy harvesting at the angular velocity of $14.4 \mathrm{rad} / \mathrm{s}$. With consideration of the theory of stochastic resonance in this research, the vibrating responses become significantly strong to generate more available energy, where the energy captured from not only the road ambient, but also its gravitational acting. Hence, the proposed energy harvester model is capable of being utilized under the vehicle tire rotation circumstances. Furthermore, the suggested application for this harvester is to provide electrical power for tire pressure sensors.
\end{abstract}

Key words : Tire rotation, Piezoelectricity, Energy harvestering, Nonlinear bistable system, Stochastic resonance

\section{1. 緒言}

低炭素社会の実現へ向けて，振動エネルギハーベスティングが注目されている．振動エネルギハーベスティン グとは，振動エネルギを電気エネルギに変換することで発電する手法である。この手法は環境振動のような，こ れまで活用されてこなかった環境エネルギを利用でき，化石燃料を必要としないことから，発電方法が効率的か つクリーンであるという長所を持つ.

既往研究における振動エネルギハーベスティングの手法としては線形システムを利用する手法が一般的である. 線形システムでは，固有振動数を環境振動の周波数と一致させることで，共振により発電効率を向上させること ができる(Leland and Wright, 2006). 線形システムを使用する場合の久点としては，振動数が変化する環境振動下 にあると，安定した発電ができないことである。この欠点は固有振動数の異なる複数の線形システムを組み合わ せれば，改善できるものの，装置が大型化してしまう(Shahruz, 2006).これに対して，広域的な周波数の環境振動

No.15-00645 [DOI:10.1299/transjsme.15-00645], J-STAGE Advance Publication date : 28 July, 2016

*1 東京大学 生産技術研究所 (T153-8505 東京都目黒区駒場 4-6-1)

*2 正員, 東京大学 生産技術研究所

*3 正員, 東京大学 大学院情報学環

E-mail of corresponding author: zysgluck@iis.u-tokyo.ac.jp 
において発電できるコンパクトな構造の非線形システムが提案されているが(Ferrari et al., 2010, Stanton et al., 2010, Arrieta et al., 2013), 環境振動が微弱であるため, 非線形システムによる出力電力が低い. そこで, 発電効率を向 上する方法が求められている，その方法として，確率共振の利用が注目されている.

確率共振現象は 1981 年に Benzi 等による地球の水河期の周期性を説明するために, 初めて提案された (Benzi et al., 1982). 確率共振とは，非線形システムにおいて微弱な信号にノイズを加えることで，ある確率 の下で応答が増幅する物理現象である。確率共振現象は近年, 多くの新しい分野に応用されている (Gammaitoni et al., 1998, Ward et al., 2006). 例えば，信号処理の分野では，確率共振を用いて微弱入力信号を 検出するシステムの研究が行われている(Klamecki, 2005, Li et al., 2014, Duan et al., 2014). また, 確率共振シ ステムをイメージセンサに応用することで, 比較的簡単に暗画像を撮像することも実現している(Moss et al., 2004, Rallabandi and Roy, 2010, Dylov and Fleischer, 2010).

機械系の分野では，非線形双安定デバイスのシステムに周期信号のほかに，ノイズを入力することで，システ ムの応答振幅を増幅させる確率共振現象が発見されている(Almog et al., 2007). その後, 確率共振を用いることで エネルギハーベスティング効率を向上する可能性が理論的に検討されている(McInnes et al., 2008). さらに，上下 方向の振動におけるノイズと微弱な外部周期力を意図的に入力することで，実験を通して非線形双安定デバイス での確率共振現象が再現されている(Zheng et al., 2014). その後, 入力振動が水平方向に変更され, 確率共振現象 発生の可能性を検討している(Nakano et al., 2014). しかしながら, 確率共振が起こる条件の下で発電された応用事 例は少ない。

一方，タイヤ用エネルギハーベスティング手法に関しては，非線形発電システムが提案され，双安定片持ち梁 構造と共にオフセット振り子を用いることで, 重力の影響を利用したシステムの有効な動作帯域幅を改善してい る(Roundy and Tola, 2014). そのほか, 複数のスプリングと質量で組み立てた非線形発電装置が開発されており, タイヤの回転による横方向重力の変化に伴って, 固有周波数を変化させることができる(Wang et al., 2015). 実際 には，発電システムを走行している車両のタイヤのリム部に設置して，重力の周方向分力を外部周期力として利 用している. 同時に, タイヤは地面の凹凸により, 路面ノイズも受ける. よって, 車両のタイヤは外部から入力 信号である周期力とノイズを同時に得られるため, 確率共振が起こるのに適した環境である. タイヤの回転で生 じる周期力のみを利用する従来までの研究と比較して, 地面ノイズにおけるタイヤの振動エネルギも利用して, 確率共振を発生させることができれば，非線形双安定デバイスの発電効率の向上が期待できる.

先行研究では, タイヤの回転環境で確率共振を発生する可能性を提案し, 適用する環境を考慮せずに, 理想的 なホワイトノイズと周期力を入力信号とし, エネルギハーベスティングの解析モデルを立てていた(Zhang et al., 2014).さらに, 発電デバイスが試作され(Zhang et al., 2015a), 確率共振現象の再現が確認されていた(Zhang et al., 2015b). しかしながら, 実際の環境振動に近い入力条件を考慮していないため, 構築したモデルの実用的な条件 下での有効性の検証が課題として残っている.

本論文では, 車両のタイヤ空気圧センサーの自立電源供給として, 車両のタイヤに実装するのに適した非線形 双安定発電デバイスを設計し, 実測した路面からの振動を周期力に加えて, 数值シミュレーションを実施するこ とによる確率共振を再現し，タイヤに向けるエネルギハーベスティングシステムの有用性を評価する.

\section{2. 手法}

\section{$2 \cdot 1$ 非線形双安定回転体のモデリング}

確率共振が発生する必要条件は, システムが非線形双安定系であることである.この条件を満足するために, 図 1 に示すような装置を提案する。この装置は単一の永久磁石, 先端に永久磁石が付けられた片持ち梁および溝 型のフレームで構成される. 単一の永久磁石は溝型のフレームの片側の側面に $\mathrm{S}$ 極側が接した状態で固定されて いる. もう一方の側面は片持ち梁の固定端になっている. 片持ち梁の先端の永久磁石は自由端と $\mathrm{S}$ 極側で結合す る. フレーム内で $2 つ の$ 永久磁石が $\mathrm{N}$ 極側で対面するように片持ち梁は配置される. 最も強い応力の生じるはり の根元には運動エネルギを電気エネルギに変換するピエゾ素子が貼り付けられている．ノイズの激励を双安定系 に加えると, 片持ち梁が永久磁石間の磁性斥力 $F_{M}$ と自身の弾性力 $k x$ の相互作用で, 非線形特性が発生寸る. そ 
の後，マグネット間の距離 $d$ を適当に調整すると，先端磁石は一つの安定点から，もう一方の安定点へ移動する 双安定性を示寸。

タイヤのリムに設置された提案された装置をモデリングする. 固定端から自由端にかけて，装置の片持ち梁の 軸がタイヤの半径方向に存在するとして, 片持ち梁先端の永久磁石の片持ち梁に対するせん断方向変位を $x$ およ び軸方向変位を $y$ とする. タイヤが回転するとき, 装置の片持ち梁先端の磁石に作用する磁力 $F_{M}$ のせん断方向 成分 $F_{H}$ は下記のように定義される.

$$
F_{H}=F_{M} \sin \theta
$$

ここで, $\theta$ は磁力が片持ち梁の軸方向と成す角を表す. Dipole モデル(Mann and Owens, 2010, Su et al., 2014)により, $F_{H}$ が下記のように表される.

$$
F_{H}=\frac{\mu v^{2}}{4 \pi}\left(\frac{3 M_{c y}\left(d M_{f x}+x M_{f y}\right)+3 M_{c x}\left(d M_{f y}+3 x M_{f x}\right)}{\left(d^{2}+x^{2}\right)^{5 / 2}}-\frac{15 x\left(x M_{f x}+d M_{f y}\right)\left(x M_{c x}+d M_{c y}\right)}{\left(d^{2}+x^{2}\right)^{7 / 2}}\right)
$$

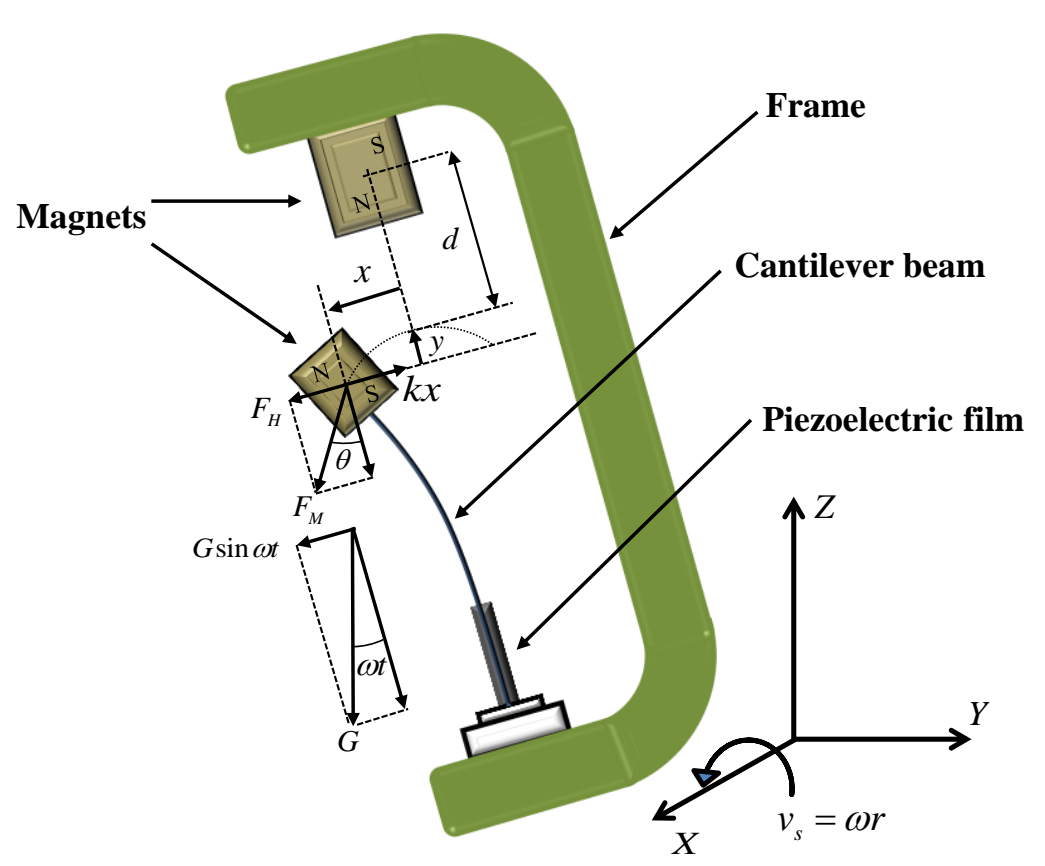

Fig. 1 Kinematic analysis through revolution modeling of the nonlinearly bi-stable energy harvester by a cantilever structure. The bi-stable system is created through positioning a magnet attached to the end of cantilever beam and another permanent magnet with the same polarity on the frame.

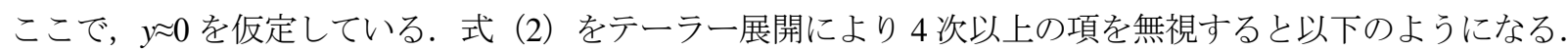

$$
F_{H} \approx\left(\mu v^{2} \frac{9 M_{c x} M_{f x}-12 M_{c y} M_{f y}}{4 \pi d^{3}}\right) x-\left(\mu v^{2} \frac{75 M_{c x} M_{f x}-90 M_{c y} M_{f y}}{8 \pi d^{7}}\right) x^{3}
$$


式(3)より $F_{H}$ が非線形力であることがわかる.ここで, $\mu$ が真空の透磁率, $v$ が磁石の体積である. $\mathbf{M}_{f}=\left[M_{f x} M_{f y}\right]^{\mathrm{T}}$, $\mathbf{M}_{c}=\left[M_{c x} M_{c y}\right]^{\mathrm{T}}$ は, それぞれ, 先端磁石と永久磁石の磁化強度である. 双安定系が半径 $r$, 回転周波数 $\omega に$ に相当す る周速度 $v_{s}$ で回る際に, 重力の作用で, 先端磁石のせん断方向の合力 $f_{H}$ と運動エネルギ $E_{K}$ が下記のようになる.

$$
\begin{aligned}
& f_{H}=F_{H}-k x+G \sin \left(\omega t+\theta_{0}\right) \\
& E_{K}=\frac{1}{2} m\left\{\left(\dot{x}+v_{s}\right)^{2}+\dot{y}^{2}\right\}
\end{aligned}
$$

式（4）において， $G$ は先端磁石に作用寸る重力， $\theta_{0}$ はタイヤ回転中心軸から見た装置取り付け位置の初期角度で あり, 鉛直上向きにある時を零とし, タイヤの回転方向の角度を正とする. ラグランジュの運転方程式に基づき, 式（6）が得られる.

$$
\frac{d}{d t}\left(\frac{\partial E_{K}}{\partial \dot{x}}\right)-\frac{\partial E_{K}}{\partial x}=F_{H}-k x+G \sin \left(\omega t+\theta_{0}\right)
$$

従って，先端磁石の運転方程式が以下のように導出できる.

$$
m \ddot{x}+c \dot{x}+\left(k-\mu v^{2} \frac{9 M_{c x} M_{f x}-12 M_{c y} M_{f y}}{4 \pi d^{3}}\right) x+\frac{\mu v^{2}\left(75 M_{c x} M_{f x}-90 M_{c y} M_{f y}\right)}{8 \pi d^{7}} x^{3}=N(t)+G \sin \left(\omega t+\theta_{0}\right)
$$

式（7）において， $c$ は粘性減衰係数, $\mu v^{2}\left(9 M_{c x} M_{f x}-12 M_{c y} M_{f y}\right) / 4 \pi d^{3}$ は磁石間の線形係数, $\mu v^{2}\left(75 M_{c x} M_{f x}-90 M_{c y} M_{f y}\right) / 8 \pi d^{7}$ は磁石間の非線形係数である. 上式で,

$$
\begin{aligned}
& a=\mu v^{2}\left(9 M_{c x} M_{f x}-12 M_{c y} M_{f y}\right) / 4 \pi d^{3}-k, \quad(a<0) \\
& b=\mu v^{2}\left(75 M_{c x} M_{f x}-90 M_{c y} M_{f y}\right) / 8 \pi d^{7}, \quad(b>0)
\end{aligned}
$$

とすると，式（10）の Duffing 方程式が得られる.

$$
m \ddot{x}+c \dot{x}-a x+b x^{3}=N(t)+G \sin \left(\omega t+\theta_{0}\right)
$$

式 (10) で, $G \sin \left(\omega t+\theta_{0}\right)$ はタイヤの回転に伴い生じる周期力であり, $N(t)$ はノイズであり, 路面不整による生じる. 本研究は, 路面ノイズの有無による確率共振発生の可能性を検討寸るので, タイヤの回転に伴うノイズの変化は 考慮していない.

\section{$2 \cdot 2$ 双安定系において確率共振が起こる条件}

提案する発電装置が回転するタイヤのリムに設置されたとき, 内部の片持ち梁先端磁石の標準的なポテンシヤ ルエネルギは式（11）よりが得らる. 


$$
U(x, t)=-\frac{1}{2} a x^{2}+\frac{1}{4} b x^{4}-G \sin \left(\omega t+\theta_{0}\right) x
$$

図 2 は, 式（11）より得られた, 非回転時のタイヤのポテンシャルエネルギの関係図である.ここで, $\theta_{0}=0$ とし ている，同図より，ポテンシャルエネルギは左右対称の井戸を有する形状となる．井戸の最梁部の位置は $x_{0}= \pm(a / b)^{1 / 2}$, 最深部の高さは $\Delta U=a^{2} /(4 b)$ となる. タイヤが回転するときは, 先端の磁石に作用寸る重力の影響で, ポテンシャルの井戸の形状が変化する. 例えば, 磁石が右に移動した場合, 右側の井戸が深くなり, 左側の井戸 が浅くなる．この時に, システムに一定強度のノイズを付加すると, 片持ち梁は左側の井戸から右側の井戸へジ ヤンプする可能性が高くなる.この条件と可能性が式（12）の Kramers レート(Hänggi et al., 1990)により定義され ている．この動作が左右に繰り返し発生すれば，確率共振現象が発生しているといえる.

$$
f<\frac{\omega_{0}}{2} \exp \left(-\frac{a^{2}}{4 b D}\right)
$$

式（12）において, $f$ は周期力の周波数， $\omega_{0}$ は双安定系の固有角振動数であり， $\omega_{0}=(2 a / m)^{1 / 2}$ と定義される. $D$ が 環境からノイズの強度である.

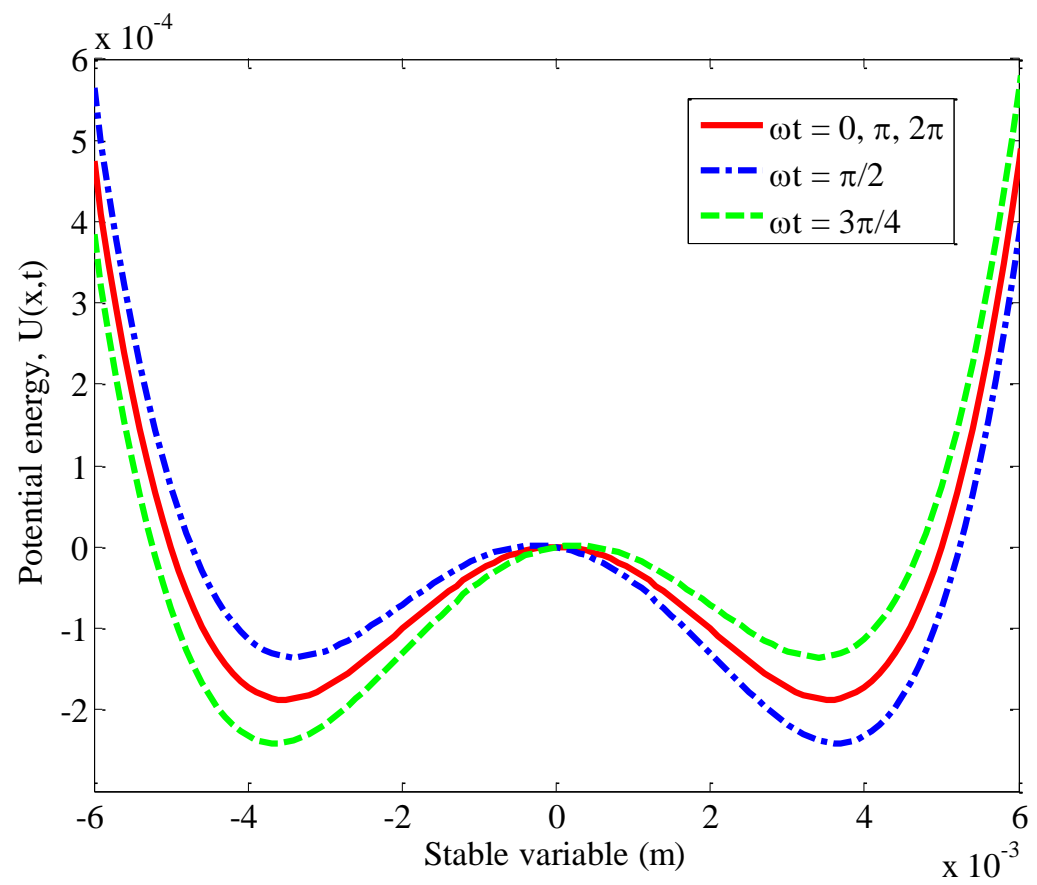

Fig. 2 Variations of the double potential wells during the whole period of the tire rotation. In the absence of the tire rotation, the double potential wells remain symmetric; however, under the condition of tire rotation, the double potential wells are asymmetrically tilted up and down, periodically raising and lowering the potential wells.

\section{$2 \cdot 3$ 発電できる電力}

振動エネルギハーベスタの一般的なモデルによれば, 粘性減数係数 $c$ は機械減衰係数 $c_{m}$ と電気減衰係数 $c_{e}$ の和 で表される，この点を考慮すると，式（10）を利用して, 以下の装置の動力に関する関係式が得られる. 


$$
\frac{d}{d t}\left(\frac{1}{2} m \dot{x}^{2}+\frac{1}{4} b x^{4}-\frac{1}{2} a x^{2}\right)+\left(c_{e}+c_{m}\right) \dot{x}^{2}=N(t) \dot{x}+G \dot{x} \sin \left(\omega t+\theta_{0}\right)
$$

式（13）において, $N(t) \dot{x}+G \dot{x}\left(\sin \omega t+\theta_{0}\right)$ は双安定系へ加える外部の機械的なパワーであり，先端磁石の重力と地 面からのノイズから提供される. 一方, $m x^{2} / 2$ および $b x^{4} / 4-a x^{2} / 2$ はそれぞれ任意の時刻 $t$ における磁石の運動工ネ ルギおよび磁石間のポテンシャルエネルギ， $c_{m} \dot{x}^{2}$ は機械的な減衰による散冕されるパワーである. よって， $c_{e} \dot{x}^{2}$ が電気減衰による回生できる電力であり, 取り出せる電力 $P$ は以下のようになる.

$$
P=c_{e} \dot{x}^{2}
$$

\section{3. 数値解析}

\section{$3 \cdot 1$ 地面ノイズの計測}

本研究では，実際のタイヤに加わるノイズを計測し，シミュレーションモデルのノイズ成分の入力とする．そ のために, 図 3 に示すように, 乗車 1 人定員のトヨタ車体の小型の電気自動車 (Coms, ZAD-TAK30-DS, トヨタ 車体株式会社) を使用し, 最高速度の $60 \mathrm{~km} / \mathrm{h}$, 前後輪タイヤ外径が $470 \mathrm{~mm}$ である. アスファルト道路上を速度 $10 \mathrm{~km} / \mathrm{h} \sim 20 \mathrm{~km} / \mathrm{h}$ で走行した時の路面からの上下方向加速度を計測する. 加速度の計測には最大応答周波数が $1000 \mathrm{~Hz}$ の三軸加速度計（MA3-20AD-RDB-SS，マイクロスートン株式会社）を使用する.タイヤが地面の上下方 向から受ける加速度を測るために, ワイヤレスの加速度ピックアップを図 4 のように前輪のサスペンションに設 置する．計測した結果より，車速 $10 \mathrm{~km} / \mathrm{h}$ から $20 \mathrm{~km} / \mathrm{h}$ において，路面からの上下加速度の振幅はほぼ一定であ った. よって, $15 \mathrm{~km} / \mathrm{h}$ で計測したノイズをシミュレーションモデルへの入力として与える. Kramers レートによ り, 確率共振が $15.3 \mathrm{rad} / \mathrm{s}$ 以下である周波数で発生しやすい.

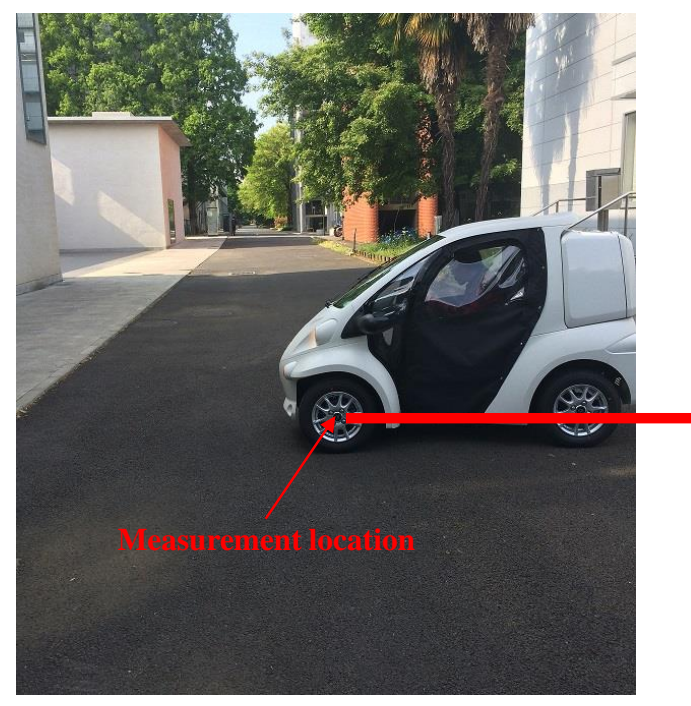

Fig. 3 Acceleration measurement on the front tire when electric vehicle travels on the normally paved road.

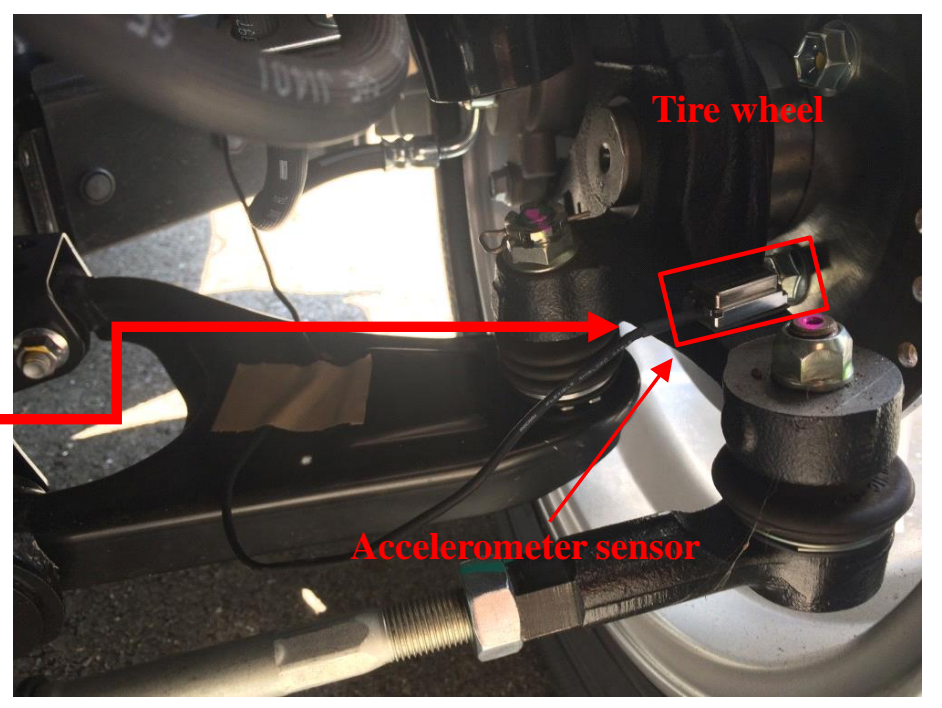

Fig. 4 A wireless accelerometer with a maximum response frequency of $1000 \mathrm{~Hz}$ is installed on the front suspension of electric vehicle, to measure the vertical road noise.

\section{$3 \cdot 2$ 数値分析}

計測したタイヤの上下方向加速度と先端磁石に作用する重力のせん断方向分力を加振力とし，確率共振を 15 $\mathrm{km} / \mathrm{h}(14.4 \mathrm{rad} / \mathrm{s})$ で発生させるのに適するパラメータを設計し, Duffing 方程式によるシミュレーションを行った. ここで，重力のせん断方向分力はタイヤの回転の影響で周期力となる．地面ノイズの強度は計算の結果， 
$D=1.35 \times 10^{-4} \mathrm{~N}$ であった。発電装置は純アルミニウム製の長方形状の片持ち梁と二つ角型ネオジム磁石

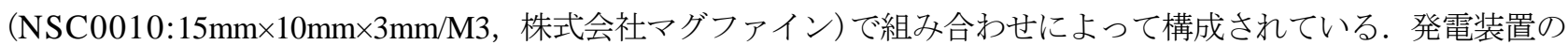
詳細なパラメータは, 磁石の磁化強度 : $M_{f x}=M_{f y}=-9 \times 10^{5} \mathrm{~A} / \mathrm{m}, M_{c x}=M_{c y}=8.5 \times 10^{5} \mathrm{~A} / \mathrm{m}$, 真空の透磁率 : $\mu=4 \pi \times 10^{7}$ $\mathrm{H} / \mathrm{m}$ ，磁石の体積 : $v=9 \times 10^{-7} \mathrm{~m}^{3}$ である.

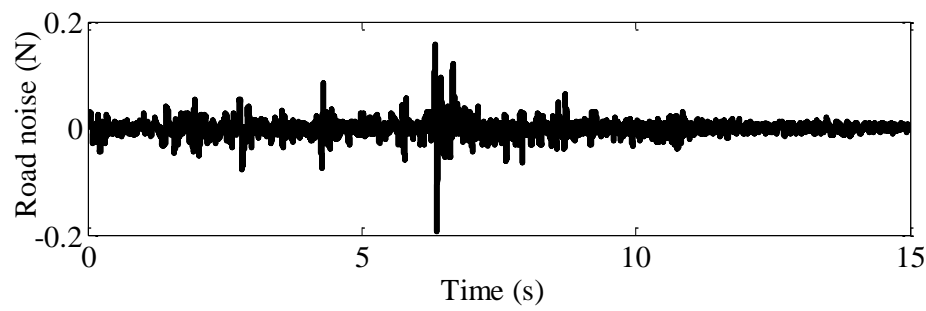

(a)

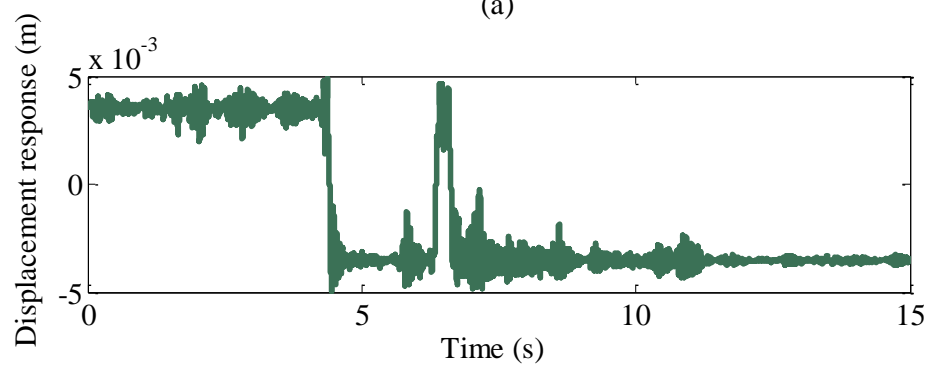

(b)

Fig. 5 (a) the measured noise from road surface, and (b) displacement response of the bistable cantilever beam only under condition of the measured road noise. The displacement response remains at a low level motion within one potential well, and the cantilever beam occasionally escapes from one stable position to another stable position.
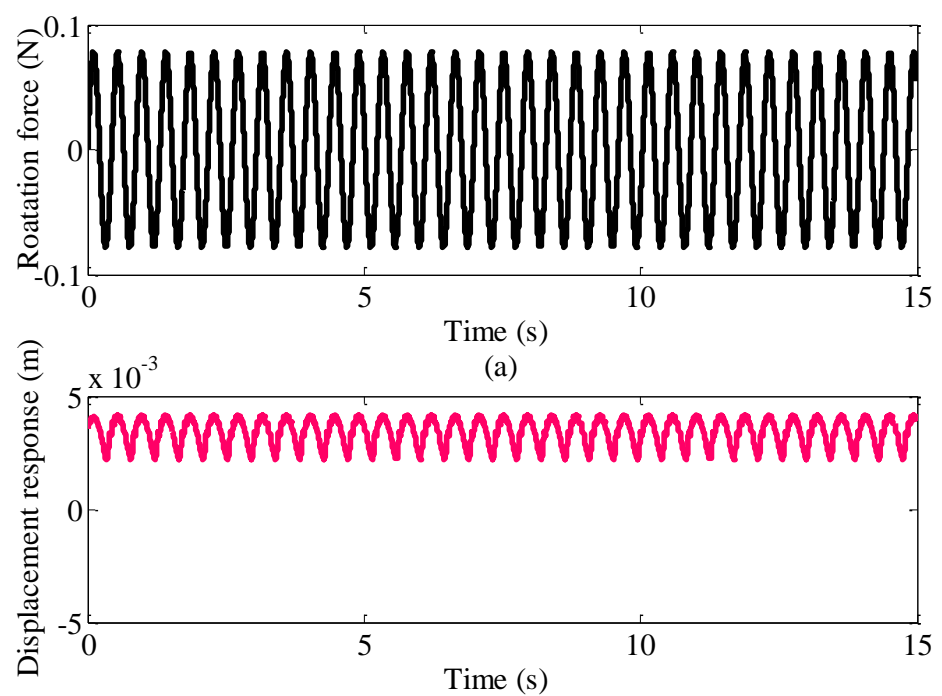

(b)

Fig. 6 (a) periodically gravitational excitation from tire rotation, and (b) displacement response of the bistable cantilever beam only under condition of the rotationally gravitational excitation. The displacement response is limited in an intra-well dynamic oscillation. 
最初に，計測したノイズのみあるいは微弱周期力のみをそれぞれシステムの加振力として与えた場合の応答波 形を考察する. 図 5 および図 6 は上図に入力信号, 下図に入力に対する応答波形を示しており, それぞれ計測ノ イズあるいは微弱周期力を入力信号としている. 図 5 (a) に示寸計測ノイズは理想的なホワイトノイズとは異な ることが確認できる．これは，地面の凹凸状況により，タイヤの接地面の圧力分布が変化するためである．この ノイズに対して, 図 5 (b) のような変位応答が得られる. 図 5 より, 比較的高振幅のノイズが生じる 4 秒付近と 6〜7 秒において, 梁が二つのポテンシャルの井戸の間をジャンプするが, それ以外の時間においては, 単安定振 動が続いている．微弱周期振動については，図 6 （a）のように振幅 $0.08 \mathrm{~N}$ の振動が入力されており，図 6 (b) に示寸応答波形では, 梁が二つのポテンシャルの井戸の間をジャンプできず, $4 \mathrm{~mm}$ 付近のポテンシャルの井戸 で微弱に振動するのが確認できる.これより, 計測ノイズと回転周期力のいずれか一方をシステムに加振しても, 連続的なジャンプ現象が現れないことを確認した。

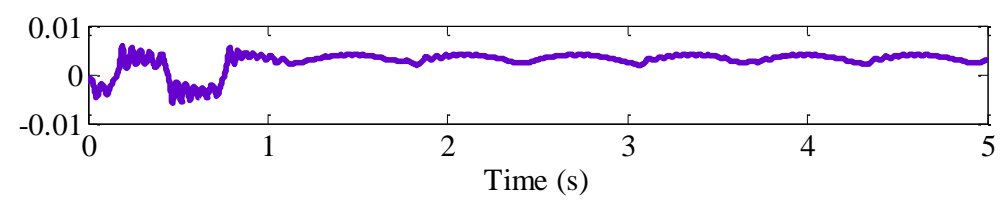

(a) $\omega=10 \mathrm{rad} / \mathrm{s}$
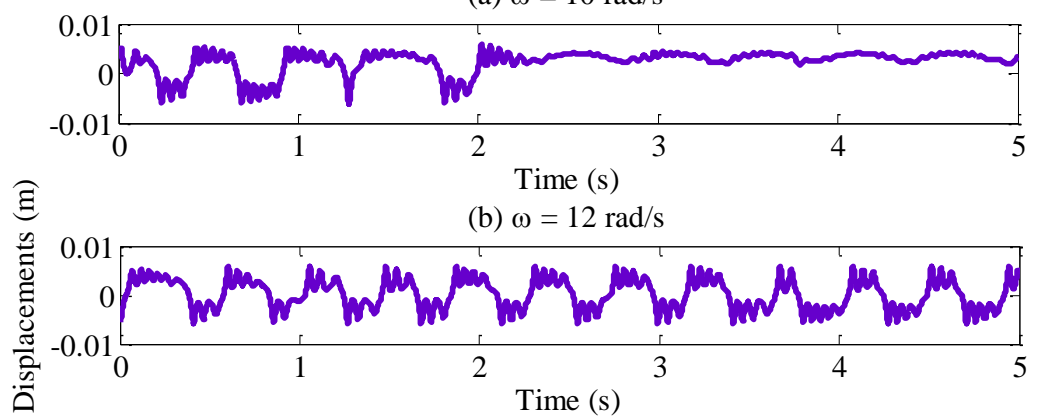

Time (s)

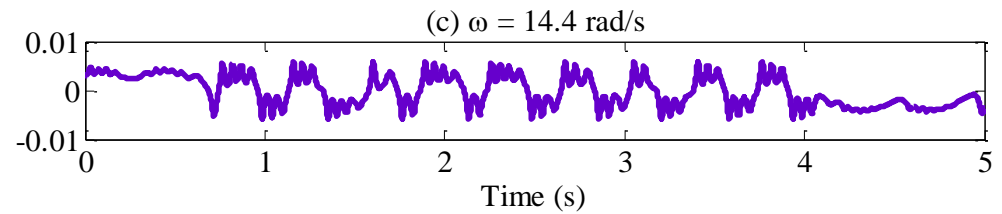

(d) $\omega=17 \mathrm{rad} / \mathrm{s}$

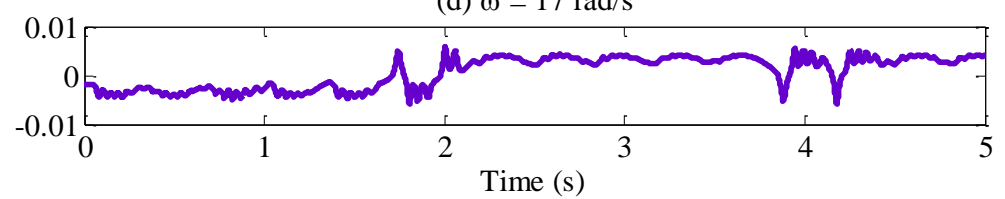

(e) $\omega=19 \mathrm{rad} / \mathrm{s}$

Fig. 7 Displacement responses under conditions of the road noise combined with the periodically gravitational excitations under different angular velocities of the tire rotation: (a) $10 \mathrm{rad} / \mathrm{s}$, (b) $12 \mathrm{rad} / \mathrm{s}$, (c) $14.4 \mathrm{rad} / \mathrm{s}$, (d) 17 $\mathrm{rad} / \mathrm{s}$, and (e) $19 \mathrm{rad} / \mathrm{s}$. When $\omega$ is $10 \mathrm{rad} / \mathrm{s}, 12 \mathrm{rad} / \mathrm{s}$, or $19 \mathrm{rad} / \mathrm{s}$, the system always fluctuates within the intra-well motion, but the displacement response sometimes jumps up and down between two potential wells. When $\omega$ is $14.4 \mathrm{rad} / \mathrm{s}$ or $17 \mathrm{rad} / \mathrm{s}$, the system can be stimulated to trigger the occurrence of inter-well motion, and the displacement response can be remained in a high level motion.

続いて, 計測ノイズと回転周期力を加振力として同時に与える場合について考察する. 回転周期力の周波数が $10 \mathrm{rad} / \mathrm{s} ， 12 \mathrm{rad} / \mathrm{s} ， 14.4 \mathrm{rad} / \mathrm{s} ， 17 \mathrm{rad} / \mathrm{s}$ および $19 \mathrm{rad} / \mathrm{s}$ であるときの，システムの変位応答をそれぞれ図 7(a)～(e) に示す. 図 7(a) (c)により, 回転周期力の周波数を $10 \mathrm{rad} / \mathrm{s}$ から $14.4 \mathrm{rad} / \mathrm{s}$ まで増加させるにつれて, 梁がポテン シャルの井戸を往復する頻度が高くなる. 一方, 周波数が $14.4 \mathrm{rad} / \mathrm{s}$ を超えると, 梁がポテンシヤルの井戸を往復 する頻度は徐々に減少していく，このシミュレーション結果より，車両の走行速度 $15 \mathrm{~km} / \mathrm{h}$ 相当する $14.4 \mathrm{rad} / \mathrm{s} の$ 振動数の回転周期力で 2 つの゚テンシャルの井戸を往復する頻度が最も高くなることが確認された. 寸なわち, 
$14.4 \mathrm{rad} / \mathrm{s}$ で連続な確率共振状態になるといえるが, $14.4 \mathrm{rad} / \mathrm{s}$ 以外での周波数帯域においても確率共振の発生する 可能性がある．発生する確率が低くなるが，片持ち梁の振幅を同程度で増加することができることで，エネルギ ハーベスティングにも有効といえる.

最後に, 計測ノイズと回転周期力を加振力としてともに与えた図 7 の応答変位に対する, 本装置のピエゾ素子 による発電能力について考察する. ピエゾ素子の電気減衰係数を $0.04 \mathrm{Ns} / \mathrm{m}$ とした場合, 電気減衰による回生で きる電力は図 8 のようになる. 回転周期力の周波数の $14.4 \mathrm{rad} / \mathrm{s}$ で確率共振現象が起こることによって, 連続的に 高効率の発電ができている. その他の回転周波数では確率共振現象が起こりにくいために, 断続的な発電現象が 見られる. しかしながら, いずれにしても, システムが双安定系であるために, ジャンプできることによって発 電できるパワーの最大值が $5 \mathrm{~mW}$ であるものの, 平均值が $14.4 \mathrm{rad} / \mathrm{s}$ で最大の $0.9 \mathrm{~mW}$ の発電電力に至っている. 更に, 図 9 に 5 秒間に蓄電できるエネルギを示す. 図 9 より, 最大が $4.4 \mathrm{~mJ}$ となり, 最小值が $0.75 \mathrm{~mJ}$ となる. この結果は, 確率共振現象の発生により, 未発生時の 5.87 倍までエネルギを取り出せることを示している. また, 本装置の確率共振現象により発電された平均電力值は $0.9 \mathrm{~mW}$ に至り, タイヤ空気圧センサーの動作に必要とす る平均電力の $3 \mu \mathrm{W}$ を上回ること分かった(Frey et al., 2010, Wu et al., 2014). 従って, 確率共振現象を利用した発電 はタイヤ空気圧センサーの電源供給として十分に使えることを示した。

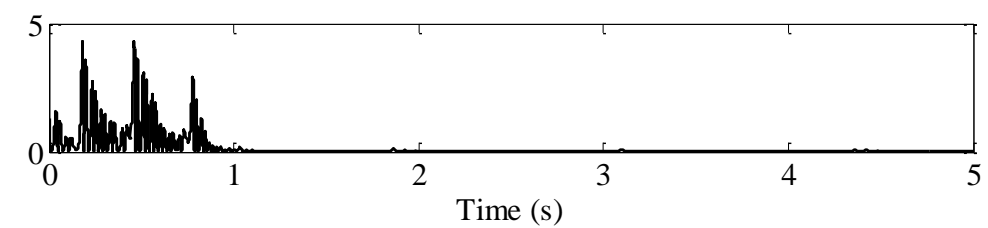

(a) $\omega=10 \mathrm{rad} / \mathrm{s}$

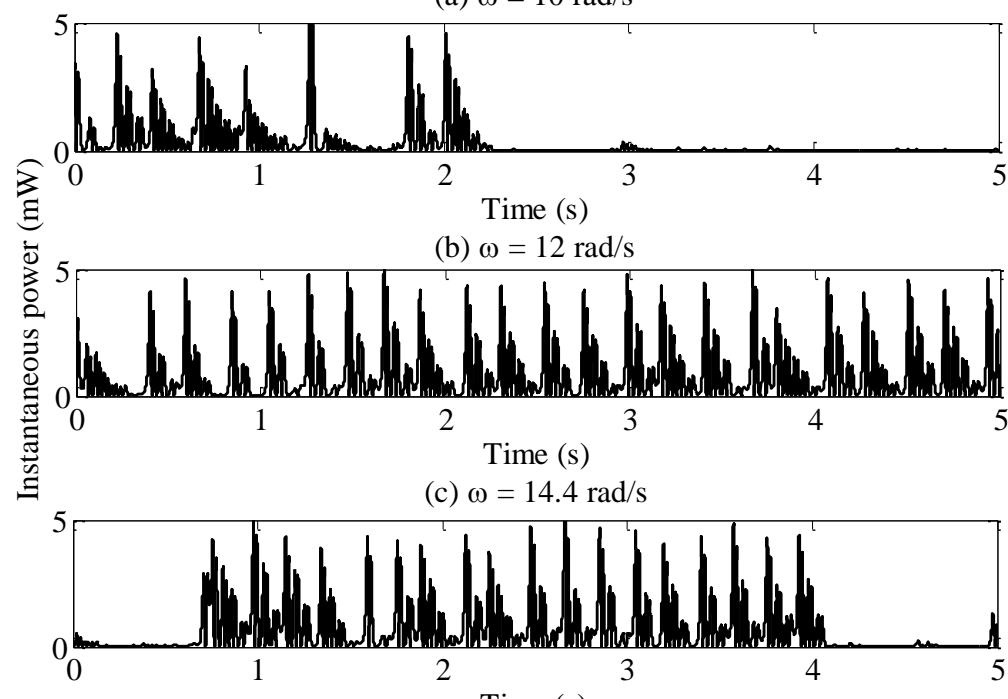

Time (s)

(d) $\omega=17 \mathrm{rad} / \mathrm{s}$

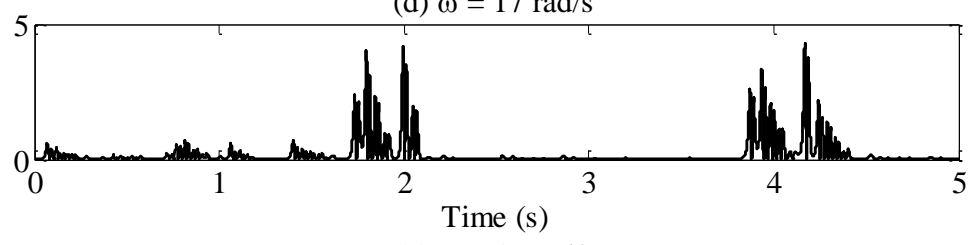

(e) $\omega=19 \mathrm{rad} / \mathrm{s}$

Fig. 8 Comparisons of the instantaneously harvested power in the case of the road noise combined with the periodically gravitational excitations under different angular velocities of the tire rotation: (a) $10 \mathrm{rad} / \mathrm{s}$, (b) $12 \mathrm{rad} / \mathrm{s}$, (c) 14.4 $\mathrm{rad} / \mathrm{s}$, (d) $17 \mathrm{rad} / \mathrm{s}$, and (e) $19 \mathrm{rad} / \mathrm{s}$. When $\omega$ is $14.4 \mathrm{rad} / \mathrm{s}$ or $17 \mathrm{rad} / \mathrm{s}$, the system can continually capture maximum power of $5 \mathrm{~mW}$. In other cases, although the harvested maximal power can still reach the same level, the probability of stochastic resonance occurring becomes significantly lower. 


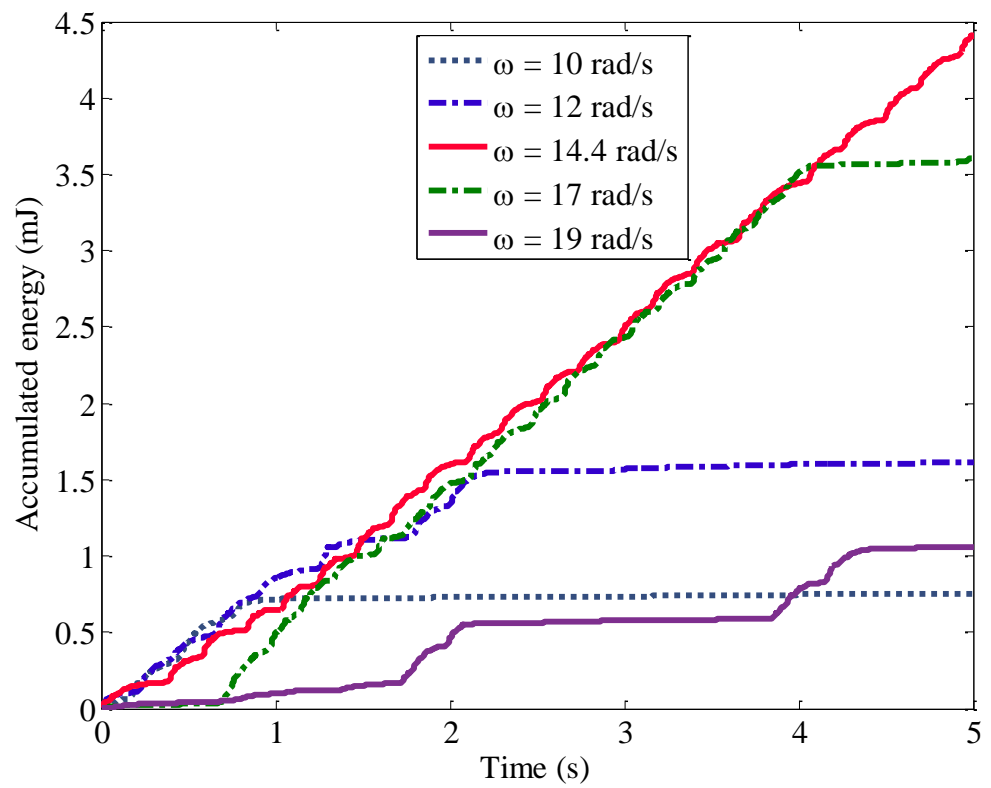

Fig. 9 Comparisons of the accumulated energy under different angular velocities of the tire rotation: $10 \mathrm{rad} / \mathrm{s}, 12 \mathrm{rad} / \mathrm{s}$, $14.4 \mathrm{rad} / \mathrm{s}, 17 \mathrm{rad} / \mathrm{s}$, and $19 \mathrm{rad} / \mathrm{s}$. The red solid curve of the $14.4 \mathrm{rad} / \mathrm{s}$ represents the fact that the obtained energy in five seconds can reach $4.4 \mathrm{~mJ}$ under the case of stochastic resonance, in which the obtained energy is nearly 5.87 times greater than that of the dotted line of the $10 \mathrm{rad} / \mathrm{s}$ under the condition of intra-well dynamic oscillation.

\section{4. 結 言}

本研究では実際の舗装路で低速走行する車両のタイヤが受けたノイズを再現し, 確率共振現象が車速 $15 \mathrm{~km} / \mathrm{h}$ で発生するようにパラメータ設計されたエネルギハーベスティングのモデルを解析した．シミュレーション結果 より, Kramers レートで計算した $15.3 \mathrm{rad} / \mathrm{s}$ に近い $14.4 \mathrm{rad} / \mathrm{s}$ で確率共振現象が発生する可能性を示した. よって, 梁の変位応答が強まる. 更に, 発電電力は, 最大值 $5 \mathrm{~mW}$, 平均值 $0.9 \mathrm{~mW}$ に達することを確認した. 従来のタイ ヤ用発電装置の低速走行におけて発電される電力值が $20 \mu \mathrm{W}$ 程度であるのと比較すると, 本装置は確率共振現象 により発電される電力值を 44 倍向上できることを示した. これより，提案する発電装置はタイヤ空気圧センサー の自立電源供給への応用に有効であると言える.

\section{謝辞}

本研究を行うにあたり，ご協力をいただいた，イギリスのシェフィールド大学 Cartmell P. Matthew 教授に謝意 を表す。

\section{References}

Almog, R., Zaitsev, S., Shtempluck, O. and Bucks, E., Signal amplification in a nanomechanical Duffing resonator via stochastic resonance, Applied Physics Letters, Vol.90, No.1 (2007), pp.013508-1-013508-3.

Arrieta, A. F., Depero, T., Bergamini, A. E. and Ermanni, P., Broadband vibration energy harvesting based on cantilevered piezoelectric bi-stable composites, Applied Physics Letters, Vol.102, No.17 (2013), pp.173904-1-173904-4.

Benzi, R., Parisi, G., Sutera, A. and Vulpiani, A., Stochastic resonance in climatic chang, Tellus, Vol.34, No.1 (1982), pp.10-16.

Duan, F., Chaeau-Blondeau, F. and Abbott, D., Stochastic resonance with colored noise for neural signal detection, PLoS ONE, Vol.9, No.3 (2014), pp.1-7.

Dylov, D. V. and Fleischer, J. W., Nonlinear self-filtering of noisy images via dynamical stochastic resonance, Nature Photonics, Vol.4, No.5 (2010), pp.323-328.

Ferrari, M., Ferrari, V., Guizzetti, M., Ando, B., Balio, S. and Trigona, C., Improved energy harvesting from wideband 
vibrations by nonlinear piezoelectric converters, Sensors and Actuators A: Physical, Vol.162, No.2 (2010), pp.425-431.

Frey, A., Seidel, J. and Kuehne, I., System design of a piezoelectric MEMS energy harvesting module based on pulsed mechanical excitation, Proceedings Power MEMS(2010), pp.29-32.

Gammaitoni, L., Hanggi, P., Jung, P. and Marchesoni, F., Stochastic resonance, Reviews of Modern Physics, Vol.70, No.1 (1998), pp.223-260.

Hänggi, P., Talkner, P. and Borkovec, M., Reaction-rate theory: fifty years after Kramers, Reviews of Modern Physics, Vol.62, No.2 (1990), pp.251-332.

Klamecki, B. E., Use of stochastic resonance for enhancement of low-level vibration signal componts, Mechanical Systems and Signal Processing, Vol.19, No.2 (2005), pp.223-237.

Leland, E. S. and Wright, P. K., Resonance tuning of piezoelectric vibration energy scavenging generators using compressive axial preload, Smart Materials and Structures, Vol.15, No.5 (2006), pp.1413-1420.

Li, X., Cao, G. and Liu, H., Aperiodic signals processing via parameter-tuning stochastic resonance in a photorefractive ring cavity, AIP ADVANCES, Vol.4, No.4 (2014), pp.047111-1-047111-8.

Moss, F., Ward, L. M. and Sannita, W. G., Stochastic resonance and sensory information processing: A tutorial and review of application, Clinical Neurophysiology, Vol.115, No.2 (2004), pp.267-281.

McInnes, C. R., Gorman, D. G., Cartmell, M. P., Enhanced vibrational energy harvesting using nonlinear stochastic resonance. Journal of Sound and Vibration, Vol.318, No.4 (2008), pp.655-662.

Mann, B. P. and Owens, B. A., Investigations of a nonlinear energy harvester with a bistable potential well, Journal of Sound and Vibration, Vol.329, No.9 (2010), pp.1215-1226.

Nakano, K., Cartmell, M. P., Hu, H. and Zheng, R., Feasibility of energy harvesting using stochastic resonance caused by axial periodic force, Strojniški vestnik - Journal of Mechanical Engineering, Vol.60, No.5 (2014), pp.314-320.

Rallabandi, V. P. and Roy, P. K., Magnetic resonance image enhancement using stochastic resonance in Fourier domain, Magnetic Resonance Imaging, Vol.28, No.9 (2010), pp.1361-1373.

Roundy, S. and Tola, J., Energy harvester for rotating environments using offset pendulum and nonlinear dynamics, Smart Materials and Structures, Vol.23, No.10 (2014), pp.105004-105014.

Shahruz, S. M., Design of mechanical band-pass filters for energy scavenging. Journal of Sound and Vibration, Vol.292, No.3 (2006), pp.987-998.

Su, D., Nakano, K., Zheng, R. and Cartmell, M. P., Stabilisation of the high-energy orbit for a non-linear energy harvester with variable damping, Proceedings of the Institution of Mechanical Engineers, Part C: Journal of Mechanical Engineering Science, DOI:10.1177/0954406214563736 (2014).

Stanton, S. C., McGehee, C. C. and Mann, B. P., Nonlinear dynamics for broadband energy harvesting: Investigation of a bistable piezoelectric inertial generator, Physica D: Nonlinear Phenomena, Vol.239, No.10 (2010), pp.640-653.

Ward, L. M., Doesburg, S. M., Kitajo, K., Maclean, S. E. and Roggeveen, A. B., Neural synchrony in stochastic resonance, attention, and consciousness, Canadian journal of experimental psychology, Vol.60, No.4 (2006), pp.319-326.

Wang, Y., Chen, C., Lin, C. and Yu, J., A nonlinear suspended energy harvester for a tire pressure monitoring system, Micromachines, Vol.6, No.3 (2015), pp.312-327.

Wu, X., Parmar, M. and Lee, D., A seesaw-structured energy harvester with superwide bandwidth for TPMS application, Mechatronics, IEEE/ASME Transactions on, Vol.19, No.5 (2014), pp.1514-1522.

Zheng, R., Nakano, K., Hu, H., Su, D. and Cartmell, M. P., An application of stochastic resonance for energy harvesting in a bistable vibrating system, Journal of Sound and Vibration, Vol.333, No.12 (2014), pp.2568-2587.

Zhang, Y., Zheng, R. and Nakano, K., Feasibility of energy harvesting from a rotating tire based on the theory of stochastic resonance, Journal of Physics: Conference Series, Vol.557, No.1 (2014), pp.12097-12101.

Zhang, Y., Zheng, R., Nakano, K. and Cartmell, M. P., Energy harvesting from vehicle tyres using stochastic resonance, The 4th Korea-Japan Joint Symposium on Dynamics and Control (2015a), pp.106-109.

Zhang, Y., Zheng, R., Kaizuka, T., Su, D., Nakano, K. and Cartmell, M.P., Broadband vibration energy harvesting by application of stochastic resonance from rotational environments, The European Physical Journal, Vol.224, No.14 (2015b), pp.2687-2701. 